\title{
Correction to: Discussion of Shue et al. "Fat Injection: A Systemic Review of Injection Volumes by Facial Subunit"
}

\author{
Timothy Marten ${ }^{1} \cdot$ Dino Elyassnia ${ }^{1}$
}

Published online: 15 August 2018

(C) The Author(s) 2018

\section{Correction to: Aesth Plast Surg}

https://doi.org/10.1007/s00266-018-1168-0

Dino Elyassnia was left off the original version of this article. The author line is correct here.

The authors would also like to correct the following errors introduced during production (corrected text in italics):

Patients who are smokers or previous smokers and patients who have undergone previous noninvasive radiofrequency and ultrasonic "skin shrinking" procedures are likely to have compromised subdermal microcirculation and micro-lymphatic vessels and as such will be less than optimal candidates for fat grafting and more likely to need more fat and several staged treatments than those who have not.

The original article can be found online at https://doi.org/10.1007/ s00266-018-1168-0.

Timothy Marten

tmarten@martenclinic.com

Dino Elyassnia

dinoelyassnia@hotmail.com

1 Marten Clinic of Plastic Surgery, 450 Sutter St, Suite 2222 ,

San Francisco, CA 94108, USA

The patient who has undergone facial ultrasonic and radiofrequency "skin shrinking" treatments is part of a growing body of patients who seem to sustain some compromise of their microcirculation and superficial microlymphatic system as a result of these and like treatments that puts them at greater risk of slough and healingrelated problems following facelift, and suboptimal take when fat grafting is performed.

Conflict of interest The authors declare that they have no conflict of interest to disclose. 